\title{
SOBREVIVÊNCIA E MORTALIDADE DAS ATIVIDADES PRODUTIVAS NO SEGMENTO DE BAIXA RENDA
}

Jaqueline Melo $^{1}$

Glaucia Vale ${ }^{1}$

Victor Corrêa ${ }^{2}$

\footnotetext{
${ }^{1}$ Pontifícia Universidade Católica de Minas Gerais - PUC Minas

${ }^{2}$ Universidade Paulista/Administração
} 


\section{Sobrevivência e Mortalidade das Atividades Produtivas no Segmento de Baixa Renda}

Resumo: O segmento informal, concentrado em comunidades de baixa renda, vem adquirindo crescente importância no Brasil e no mundo. Sua lógica, no entanto, permanece pouco compreendida. Nesse contexto, um tema relevante diz respeito à temática da sobrevivência $\mathrm{e}$ mortalidade desses empreendimentos. Embora existam pesquisas sobre o tema da mortalidade, estas são voltadas, exclusivamente, para a análise de empresas formalmente constituídas, sobretudo de micro e pequeno porte. O presente trabalho busca, a partir da literatura existente, avançar na busca das causas de sobrevivência e mortalidade dessas atividades produtivas informais. Para isso, foi realizada adaptação das categorias analíticas presentes na literatura corrente (indivíduo, atividade, ambiente). Elas foram utilizadas, de maneira pioneira, na análise de quatro atividades produtivas urbanas (duas ativas e duas extintas). Resultados permitem constatar a noção de que esses empreendimentos são dotados de lógica peculiar, exigindo revisão de alguns conceitos analíticos e novas pesquisas..

Palavras-chave: Informalidade. Sobrevivência. Mortalidade. Empreendedorismo. 


\section{Introdução}

A pobreza é um fenômeno complexo (Sen, 2010), com múltiplas dimensões e facetas adicionais, incluindo desigualdade, exclusão e informalidade (Márquez, Reficco, \& Berger, 2010). Nesse contexto, as questões envolvendo trabalho e renda adquirem relevância ímpar. Assegurar trabalho "decente" é componente essencial para a promoção do desenvolvimento socioeconômico, o combate à pobreza e a redução das desigualdades sociais (Leone, 2010). Entende-se por trabalho decente a promoção de emprego e ocupação com proteção social, respeito aos direitos e princípios fundamentais no trabalho e diálogo social (Leone, 2010). De acordo com o Relatório do Banco Mundial (2015), para os pobres e vulneráveis, o emprego é o caminho principal para sair da pobreza. No entanto, mais de um bilhão de pessoas em idade ativa não estão participando da força de trabalho formal. Muitas dessas pessoas vão buscar, na atividade produtiva informal, fonte alternativa de renda.

De acordo com os dados do Ministério da Fazenda (2010), existem 10.335.962 empreendimentos informais no Brasil (Viana, Teixeira, \& Franca, 2013). Estes empreendimentos se localizam em centros urbanos e produzem cerca de $17 \%$ do PIB brasileiro, gerando cerca de 573 bilhões de reais (Cupertino \& Mendonça, 2012). Para o Serviço Brasileiro de Apoio às Micro e Pequenas Empresas (SEBRAE) (2007), as atividades informais compreendem as unidades econômicas pertencentes aos trabalhadores por conta própria e aos empregadores com até cinco empregados, incluindo os proprietários (sócios) desses empreendimentos (Viana et al., 2013). Segundo Pochmann (2008), as unidades de micro empreendimento informal no Brasil compreendem amplo, complexo e extremamente heterogêneo conjunto de atividades. Varia desde porta de absorção de desempregados sem alternativas no mercado de trabalho, passando pelo exercício de atividades artesanais, até a constituição de iniciativas pré-capitalistas com potencial de expansão.

Esse amplo e variado segmento de interesse, no Brasil, é formado por autônomos, trabalhadores por conta própria, camelôs, donos de pequenas oficinas, botecos, etc, localizados, sobretudo, nas periferias dos centros urbanos ou no interior, funcionando como importante alternativa de geração de trabalho e renda, construída à margem da lei. Atualmente, na maioria dos países, sejam eles desenvolvidos ou subdesenvolvidos, prolifera vasta gama de atividades econômicas que, fugindo às obrigações tributárias, deixam de pertencer ao mercado formal (Maia, 1999; Warren, 2003).

O tema da informalidade, no segmento de baixa renda, vem sendo objeto de inúmeras pesquisas. Valarelli e Vale (1997), por exemplo, realizaram um dos estudos pioneiros no Brasil, enfocando pequenos estabelecimentos produtivos informais, localizados nas favelas e periferias da cidade do Rio de Janeiro. Vários outros estudos abordam a temática da informalidade no país, como por exemplo, Santos, Maciel, Sato e Santos (2014), Leone (2010), Viana et al. (2013), Warren (2003), Theodoro (2000), Rakowski (1994), Pamplona e Romeiro (2002), dentre outros.

O surgimento do interesse pelo tema da mortalidade de empresas, no Brasil, foi capitaneado, inicialmente, pelo SEBRAE. A instituição realiza, desde 1998, estudos regulares para monitorar a sobrevivência dos novos empreendimentos (ver, por exemplo, Vale, Aguiar, \& Andrade, 1998). Após essa iniciativa, surgiram inúmeras pesquisas, inclusive algumas de natureza periódica, como por exemplo: o "Anuário do trabalho na micro e pequena empresa" e o "Monitoramento da sobrevivência e mortalidade de empresas" do SEBRAE/SP. O tema vem

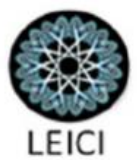


sendo explorado por diferentes autores como Albuquerque (2013), Cazarini, Santos, Oliveira Neto e Oliveira (2008), Dias, Gonçalves e Augusto (2014), Dutra e Previdelli (2005), dentre outros. Observa-se, no entanto, que a maior parte dos artigos foi elaborada por economistas ou sociólogos, deixando à margem analistas organizacionais. Pesquisas realizadas junto a alguns dos principais periódicos de administração (RAC, RAE, O\&S, RAUP) e em congressos da área (EnANPAD, Eneo, Egep, Semead), nos últimos 10 anos, não se registraram a presença de investigações resultantes da associação entre o tema sobrevivência e mortalidade de empresas e o tema da informalidade.

O presente trabalho busca, a partir da literatura existente, avançar na busca das causas de sobrevivência e mortalidade das atividades produtivas informais localizadas no segmento de baixa renda. Entende-se por atividades produtivas informais aquelas em que os indivíduos/empreendedores são movidos pela necessidade de sobrevivência, visando seu sustento e de suas famílias, concentradas, predominantemente, em comunidades de baixa renda. Apresenta, na primeira parte, o referencial teórico, buscando associar o tema da informalidade com a temática da sobrevivência e mortalidade. Gera, a partir daí, modelo de análise adaptado ao segmento de interesse.

$\mathrm{Na}$ segunda parte, apresenta-se a metodologia e os resultados gerais obtidos com o estudo de casos múltiplos (duas atividades ativas e duas extintas). Observa-se que os fatores experiência prévia, dedicação e personalidade do indivíduo, instrumentos de trabalho que utiliza, além da sua noção de concorrência como fonte de estímulo e aprendizado foram importantes para a sobrevivência. Finalmente, nas considerações finais (terceira parte), pondera-se sobre a natureza particular da dinâmica e da lógica desse segmento, o que exige revisão de categorias e conceitos analíticos até então vigentes. Novas pesquisas, que enfoquem esse rico e complexo tecido sócio econômico, deverão considerar tais elementos.

\section{Referencial Teórico}

Em meados dos anos 70, o termo "setor informal" passou a fazer parte do jargão oficial. Criado no seio da Organização Internacional do Trabalho (OIT), tal conceito aparece como novo instrumento explicativo para um velho fenômeno: a existência de atividades econômicas de baixa produtividade e que se desenvolvem à margem da legislação (Ferreira, 2009). Ao longo dos anos, o debate sobre o setor informal tem aumentado em complexidade (Rakowski, 1994). Diferentes termos passaram, aí, a serem cunhados. Destacam-se: economia subterrânea, invisível, clandestina, oculta ou informal (Portes \& Schauffler, 1993).

A partir dos anos 2000, a informalidade no segmento de pequenos negócios - até então expressão de problemas históricos e estruturais de uma economia em desenvolvimento - passou a resultar, também, da estagnação relativa da economia brasileira (Santos, Krein, Calixtre, 2012). Visando reverter esta situação, diferentes iniciativas públicas e privadas passaram a serem edificadas nos últimos 20 anos. Inserem-se aí aquelas conduzidas pelo Sistema Nacional de Empregos (SINE), pela hoje extinta Legião Brasileira de Assistência (LBA), e mais recentemente pelo o Conselho Deliberativo do Fundo de Amparo ao Trabalhador (CODEFAT) e pelo Banco Nacional de Desenvolvimento Econômico e Social (BNDES) (Theodoro, 2000). Uma delas, conduzida pelo SEBRAE, merece particular destaque. Com o objetivo de retirar da

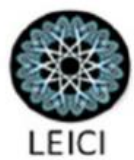


informalidade milhões de empreendedores e facilitar a abertura de novos negócios, a empresas instituiu a figura do 'Empreendedor Individual' (EI). Com ela, empreendedores que faturam até $\mathrm{R} \$ 60.000,00$ (Sessenta mil reais) por ano, não possuem participação em outra empresa como sócio ou titular e que empregam até um trabalhador podem se formalizar como EI (Vianna, Teixeira, \& Franca, 2013).

A despeito das diversas iniciativas de apoio ao empreendedorismo informal, diferentes motivos impactaram, ainda assim, em aumento do número de empreendimentos informais no Brasil nos últimos anos (Santos, 2006; Santos et al., 2012). Inserem-se, aí: reduzida qualificação profissional, baixa instrução formal e pouco capital acumulado (Santos et al., 2012). Com efeito, muitos empreendedores informais são, ao mesmo tempo, movidos por necessidades. Isto é, influenciados pela incapacidade de encontrarem melhores alternativas de trabalho e renda, muitos indivíduos acabam por se veem obrigados a criarem pequenos empreendimentos, usualmente informais, como forma de sobrevivência.

Conquanto possam gozar de certas similaridades com os empreendimentos formais, negócios informais tendem a possuir diferentes particularidades. Salienta Montenegro (2013), por exemplo, como tais empreendimentos, por se concentrarem em parcelas desvalorizadas do tecido urbano e por possuírem baixo nível de capitalização, necessitam de escala mínima de mercado, suficiente para permitir perpetuar sua existência. Neste sentido, seriam as redes locais as responsáveis por sustentar os empreendimentos. De fato, salienta Marques (2010) como a participação em determinadas redes de sociabilidade desdobra-se, muitas vezes, na prestação de pequenos serviços entre os próprios membros das redes. Além disso, diferentes outros fatores associados à peculiaridade de empreendimentos informais poderiam, também, se inserir ai. Destacam-se, por exemplo: i.) grande vulnerabilidade; ii.) precariedade de recursos; iii.) instabilidade produtiva; iv.) caráter refratário a mecanismos convencionais de políticas públicas; v.) ausência de alternativas; vi.) heterogeneidade; vii.) pequena escala; viii.) ausência de distinção entre capital e trabalho; ix.) baixa produtividade, entre outros.

Nesse contexto, à análise de empreendimentos informais, alguns dos fatores/causas de sobrevivência e mortalidade elencados devem ser abandonados; outros, por sua vez, podem ser utilizados com cautela, como referência preliminar. Observa-se que quanto menor ou mais vulnerável for o negócio formal sob análise, mais próximo, à princípio, ele poderia estar da lógica do segmento informal de baixa renda. Nesse sentido, pesquisas sobre mortalidade no segmento de microempresas estariam mais próximas do universo de interesse do presente trabalho. As microempresas situar-se-iam, algumas vezes, em uma fronteira eventualmente movediça e fluida entre os segmentos informal e formal. De fato, alguns autores fazem menção a essa zona de transição entre a atividade informal e a microempresa (Valarelli \& Vale, 1997). Salientam como, em contextos desfavoráveis, microempresas podem passar à informalidade. Da mesma maneira, em contextos muito favoráveis, pequenas unidades produtivas informais, inclusive as de baixa renda, podem se formalizar, transformando-se em microempresas ativas no mercado (Valarelli \& Vale, 1997).

De modo geral, a literatura na área de sobrevivência e mortalidade de empresas é ampla e diversificada. $\mathrm{O}$ presente estudo analisou 26 artigos que abordam as temáticas no segmento de micro, pequenas e médias empresas (Albuquerque, 2013; Cazarini et al., 2008; Dias et al. 2014; Dutra \& Previdelli, 2005; Eckert, Mecca, Blasio, \& Macari, 2013, entre outros). O número de artigos se baseou na saturação teórica. Sua seleção foi feita com base em palavras-

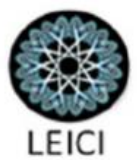


chave nos títulos dos trabalhos. Foram identificados e analisados os motivos ou fatores intervenientes no processo de sobrevivência ou mortalidade. Da análise, foi possível elencar amplo conjunto de variáveis associados ao fenômeno. A partir dá́, buscou-se classificar e agrupar as variáveis teóricas em conjuntos de categorias (Tabela 1). Para isso, utilizou, em primeiro momento, o modelo proposto por Ferreira, Santos, Oliva, Grisi e Lima (2012). Nele, os fatores de sobrevivência e mortalidade poderiam ser condensados em três grandes grupos, a saber: a) inerentes ao empreendedor; b) relativos ao negócio; e c) relacionados ao ambiente externo do negócio.

Quadro 1. Classificação dos fatores de sobrevivência e/ou de mortalidade segundo as categorias da literatura corrente

\begin{tabular}{|c|c|}
\hline Categorias & Fatores \\
\hline Empreendedor & $\begin{array}{l}\text { Competência, experiência e negligência; Conhecimento técnico; Recursos do } \\
\text { proprietário; Comportamento empreendedor; Gestão empresarial; Nível de } \\
\text { escolaridade; Estilos de liderança; Capacidade de assumir riscos; Motivação; Perfil, } \\
\text { quantidade, problemas pessoais e remuneração de sócios; Sexo do proprietário; } \\
\text { Escolha de um bom administrador; Persistência/perseverança; Criatividade e } \\
\text { inovação; Aproveitamento de oportunidades; Relacionamentos profissionais, } \\
\text { pessoais e familiares; Tradição familiar; Tipos de personalidades e estilos de } \\
\text { aprendizagem; Foco no negócio e na identificação de oportunidades. }\end{array}$ \\
\hline Empresa & $\begin{array}{l}\text { Dificuldades financeiras; Plano de negócio; Quantidade de vendas; Capital de giro; } \\
\text { Competitividade; Qualidade da mão de obra; Visão estratégica; Apoio profissional; } \\
\text { Capacidade de inovação; Natureza da Clientela; Capacidade de pagamento do } \\
\text { cliente; Ponto/Local e instalações; Relação com o fisco; Satisfação do cliente; Porte } \\
\text { da empresa; Capacidade de reinvestir os lucros da empresa; Aproveitamento das } \\
\text { oportunidades do negócio; Capacidade de compor preços; Informações sobre o } \\
\text { negócio, produto, mercado e oportunidades; Qualidade dos produtos e serviços; } \\
\text { Estoques; Despesas operacionais; Ativos e lucros; Utilização de lições aprendidas; } \\
\text { Expectativa futura; Habilidades de marketing; Organização e adequação dos } \\
\text { produtos; Flexibilidade financeira para institucionalizar departamentos de pesquisa } \\
\text { e desenvolvimento ou estabelecer convênios com universidades com o objetivo de } \\
\text { gerar inovações; Barreiras para a compra de equipamentos sofisticados e realização } \\
\text { de gastos com propaganda; Poder de barganha por conta das diminutas escalas de } \\
\text { produção. }\end{array}$ \\
\hline Ambiente Externo & $\begin{array}{l}\text { Burocracia legal e fiscal; Concorrência; Pressão dos clientes; Fornecedores, } \\
\text { representantes, distribuidores e parceiros; Natureza do mercado; Ciclo econômico: } \\
\text { aquecimento versus recessão econômica; Mercado consumidor ; Apoio institucional } \\
\text { ao empreendedorismo; Acesso a novas tecnologias; Disponibilidade de crédito; } \\
\text { Diversidade de fontes de informação; Políticas de apoio. }\end{array}$ \\
\hline
\end{tabular}

À luz das análises do setor informal até aqui apresentadas, é possível afirmar, à princípio, serem as atividades informais dotadas de dinâmica diferenciada, particular. Uma delas é a de que os setores informais seriam caracterizados por unidades produtivas pequenas, compostas, muitas vezes, por única pessoa (o dono, ou empreendedor ou autônomo). Quando imersos, ao mesmo tempo, em comunidades de baixa renda (periferias ou favelas), tais indivíduos se caracterizariam, também, por possuírem baixa escolaridade, pouca ou nenhuma experiência ou trabalho assalariado. Além disso, explorariam atividades voltadas principalmente à própria

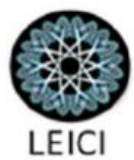


subsistência, movimentando conjunto pequeno de recursos, inclusive financeiros, e se voltando ao atendimento das necessidades dos locais onde habitam. Disto resultaria a constatação de que seus "mercados" seriam, de maneira geral, restritos, isto é, limitados, muitas vezes, a conhecidos, amigos e associados.

Levando-se em consideração tais peculiaridades, foi-se edificado, a partir de quadro proposto por Ferreira et al. (2012), novo modelo categórico, mais aderente às características e peculiaridades do segmento informal. Isto é, se por um lado alguns fatores podem se adequar aos empreendimentos formais, dentre os quais se inseririam, por exemplo, "problemas particulares com os sócios", "escolha de um bom administrador" ou, então, "presença de mão de obra qualificada", no contexto informal eles perdem relevância. Diante disto, as categorias propostas por Ferreira et al. (2012) (Empreendedor, Negócio e Ambiente Externo), adequadas à análise de empreendimentos formais, foram ajustadas, considerando-se o caráter muitas vezes precário, pouco estruturado e instável das atividades informais. Da análise, criou-se três novas categorias, denominadas: i.) indivíduo (ou empreendedor); ii.) atividade produtiva (ou negócio), e; iii.) ambiente socioeconômico (ou ambiente externo).

O resultado dessas reflexões, advindos do cotejamento entre, por um lado, as características do segmento informal e, por outro, as categorias e fatores de sobrevivência e mortalidade, permitiram a elaboração de modelo preliminar de análise para o fenômeno de interesse (Tabela 2).

Quadro 2. Categorias de análise propostas e respectivos fatores associados

\begin{tabular}{l|l}
\hline \multicolumn{1}{c|}{ Categorias } & \multicolumn{1}{c}{ Motivos/Fatores passíveis de análise no segmento informal } \\
\hline Indivíduo & $\begin{array}{l}\text { Experiência prévia; escolaridade básica; capacidade de iniciativa; impacto do fator } \\
\text { gênero; parcerias; redes de apoio; natureza dos laços, etc. }\end{array}$ \\
\hline Atividade Produtiva & Capital de giro; crédito; presença de auxiliares; clientela; localização; etc. \\
\hline $\begin{array}{l}\text { Ambiente Sócio } \\
\text { Econômico }\end{array}$ & $\begin{array}{l}\text { Acesso ao crédito; concorrência; fornecedores; informação sobre oportunidades; apoio } \\
\text { institucional; impacto dos ciclos econômicos; papel de conhecidos; amigos e parentes; } \\
\text { etc. }\end{array}$ \\
\hline
\end{tabular}

\section{METODOLOGIA E RESULTADOS OBTIDOS}

A estratégia de pesquisa foi qualitativa, com apropriação de evidências qualitativas (ver: Bauer, Gaskell, \& Allum, 2002; Bonoma, 1985; Creswell, 2007; Gaskell, 2002; Godoy, 1995a; Godoy, 1995b; Godoy, 1995c; Godoy, 2005; Minayo, Souza, \& Santos, 2005). De natureza descritiva (Godoy, 2006; Ridder, Hoon, \& McCandless, 2009; Yin, 2010), tal pesquisa é indicada às investigações que visam descrever fenômenos dentro de seu contexto (Ridder et al., 2009). O tipo de projeto foi múltiplo (Aaboen et al., 2012; Aaboen et al., 2012; Eisenhardt, 1989; Godoy, 1995c, 2006; Meyer, 2001; Ridder et al., 2009). A análise, considerada uma das etapas mais difíceis dos estudos de caso (Yin, 2010), compreendeu no "exame, na categorização [e] na tabulação das evidências [...] para tirar conclusões baseadas empiricamente" (Yin, 2010, p 154). À análise qualitativa, foi empregada a estratégia da "generalização analítica" (Yin, 2010). A categorização dos dados se deu em três etapas distintas: Na primeira, a busca dos fatores de sobrevivência e mortalidade resultou em total de 75 (setenta e cinco) categorias. Cada categoria constituiu-se de trechos selecionados das falas dos entrevistados, associados, ao

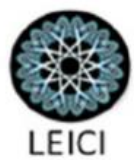


mesmo tempo, às categorias identificadas na literatura acerca das temáticas de interesse. A segunda, destinada ao refinamento da primeira, por sua vez, resultou na constituição de 19 (dezenove) categorias intermediárias. Finalmente, na terceira foi realizada a classificação e a agregação dos dados, escolhendo as categorias teóricas ou empíricas, responsáveis pela especificação do tema. As categoriais iniciais e intermediárias apresentadas anteriormente ampararam a construção das categorias finais, sendo as mesmas constituídas por três grandes grupos denominados: "Indivíduo", "Atividades produtivas informais" e "Ambiente Sócio Econômico".

As unidades empíricas de análise foram quatro unidades produtivas informais localizadas na Região Metropolitana de Belo Horizonte e beneficiárias do Programa de "Apoio ao Empreendedorismo", da Rede Cidadã. A Rede Cidadã é uma Organização Social, de âmbito Nacional, sem fins lucrativos, cuja missão é "promover a cidadania, constituindo redes de voluntários, empresas, sociedade civil e governo, gerando maior valor social" (Rede Cidadã, 2015). Das quatro atividades produtivas investigadas, duas estavam, quando da coleta de dados, ativas há mais de dois anos, e duas estavam extintas pelo mesmo período. Observa-se que a Rede Cidadã forneceu, inicialmente, relação de cerca de quarenta pessoas por ela atendidas (todas mulheres). Temendo discutir o assunto informalidade, dado o caráter ilegal da qual se reveste tais unidades, a maioria recusou-se a participar das entrevistas. As identidades dos empreendedores foram, por motivos éticos, preservadas. Visando manter sua privacidade, a nomenclatura adotada foi "A" e "B" para ativas, "C" e "D" para extintas.

Com 56 anos de idade, a primeira empreendedora " $A$ " é divorciada e mora com uma filha de 37 anos, sua ajudante, em bairro da periferia de Belo Horizonte/MG, onde produz pães, roscas, biscoitos, salgados e marmitex para venda, garantindo o sustento de ambas. De origem modesta, foi acostumada a trabalhar nos serviços domésticos desde sua infância (com 8 anos de idade), momento em que relata ter aprendido a cozinhar apenas observando sua mãe nos afazeres da cozinha. Trabalhou em várias casas de família, inclusive com carteira assinada, onde desenvolveu algumas de suas habilidades e adquiriu alguns contatos.

Com escolaridade limitada (apenas a $4^{\mathrm{a}}$ série do Ensino Fundamental), demonstra possuir garra, força de vontade e capacidade de trabalho. Quando pensou em trabalhar por conta própria, tomou conhecimento da Rede Cidadã, onde buscou apoio. A partir desta parceria, ela pode participar de curso de Informática e outros, além de assistir a palestras sobre temas diversos. Seu linguajar reflete seu senso de observação e, também, suas idiossincrasias. Para ela, o conceito de lucro apresenta-se como um conceito de sobra, "o lucro é a sobra". Referindose a uma iniciativa para atender uma demanda grande, onde teve que se associar a outros produtores, para dividir as despesas, explica como chegou às sobras: "esse aqui sobrou, aí são as sobras. É divido em partes iguais para todos que trabalharam. Isso é o que gente chama de sobra". Nesse mesmo relato, observa-se como consegue sobreviver sem crédito, compartilhando custos com eventuais parceiros. Seus contatos, como amigas, antigas patroas, profissionais da Rede Cidadã foram considerados muito importantes para a sobrevivência de seu negócio.

Como não possui um endereço fixo para a comercialização dos produtos, "A" realiza a produção em sua residência e comercializa em feiras e eventos organizados por diversas instituições parceiras da Rede de Economia Solidária de Belo Horizonte, como o Instituto Paulinus, Instituto Promovendo, SEDESE, Instituto Karitas, Instituto Maristas, dentre outros.

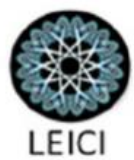


Como pontos fortes do empreendimento, "A" ressalta a presença das parcerias, especialmente da Rede Mineira de Economia Solidária e da Rede Cidadã e a qualidade de seus produtos. Como pontos de fragilidade, ela destaca a dificuldade de acesso ao crédito. Segundo ela, sua trajetória, como empreendedora, lhe permitiu lição de sobrevivência e melhor a qualidade de vida. Seu sonho é crescer e poder contratar mão de obra para lhe ajudar.

Com 47 anos de idade e ensino médio técnico em decoração, concluído em 1997, a segunda empreendedora "B" é divorciada e possui dois filhos, com idades de 29 e 31 anos. O interesse pela decoração é antigo, mas a atividade não começou como sua fonte de renda. Quando casada, a decoração era tida como satisfação pessoal e era utilizada apenas em sua casa. Quando se formou, ela teve oportunidade de assistir a uma palestra sobre Feng Shui e decidiu que era nessa linha que gostaria de trabalhar. Começou a atividade de maneira irregular, pois a vida pessoal começava a ficar desorganizada.

Após o divórcio, os filhos foram morar com o pai, ela perdeu grande parte da renda que era de aluguel, e não pôde manter as despesas. De repente se encontrou "sem teto, sem nada, sem rumo". A partir daí ela ficou fazendo pequenos "bicos", chegou a trabalhar como vendedora em uma loja de roupas e começou a ministrar palestras. Relata que às vezes em um salão para 200 pessoas, havia duas pessoas para ouvir falar de Feng Shui, e ela dava a palestra assim mesmo. Cansada de passar dificuldades, inclusive, algumas vezes, fome, decidiu investir em seu "dom" e criou, em 2007, sua atividade produtiva de Feng Shui.

Foi nesta ocasião que surgiu oportunidade de trabalhar de maneira formal. De acordo com "B", de certa forma uma empresa a obrigou a ser um negócio formal, devido à necessidade de possuir CNPJ, contador, nota fiscal, etc. Nessa época, a empreendedora tentou a sociedade com uma amiga, que funcionou durante algum tempo, até que, finalmente, continuou sozinha. Após idas e vindas, oscilando nos negócios e no nível pessoal, fechou sua empresa e começou a trabalhar como massagista, de maneira informal.

O Feng Shui, no entanto, continuou a ocupar sua imaginação. Em 2009 voltou a trabalhar, novamente, de maneira informal, no ramo. Passou a se dedicar a ele, de corpo e alma e o negócio prosperou. Chegou a ter uma secretária e uma assistente, voluntária. Criou seu próprio blog e sua página no Facebook, onde divulga seu trabalho, atendendo em residências. Entre seus parceiros (aliados) nessa empreitada, cita a Rede Cidadã e a ABD (Associação Brasileira de Decoração).

Com 47 anos de idade e ensino médio completo, a terceira empreendedora "C" é viúva e mora com seus cinco filhos, com idades de 20,18,16, 15 e 13 anos. Após o casamento, com a chegada dos filhos, ficou difícil para sair de sua casa, localizada no Bairro Veneza, em Venda Nova, e ir trabalhar em Belo Horizonte, onde, anteriormente, havia sido empregada em uma Farmácia. Seu período como vendedora deu-lhe, segundo ela, segurança e experiência para lidar com o público, além de conhecer procedimentos que a auxiliaram no momento em que começou a lidar com a venda de seus produtos, chinelos decorativos. Seu negócio, iniciado em 2009, foi um dos projetos apoiados pela Prefeitura de Venda Nova.

Seu primeiro contato com o ramo de atividade foi por meio de cursos de artesanato, realizados no próprio bairro. Lá, encontrou uma moça que bordava e então se interessou e aprendeu o ofício. Na ocasião, era apenas uma complementação de renda. Com a morte de seu esposo, tendo que sustentar uma grande família, o negócio tornou-se importante fonte de renda, ao lado da pensão do marido. A produção era realizada em sua residência e contava com a

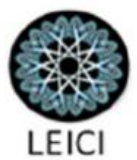


parceria de uma amiga. Chegavam a vender, em média, 100 pares de chinelos/mês. O ponto de venda era uma barraca, em um espaço cedido pela Prefeitura supracitada. Sua clientela era formada, em grande parte, por uma rede direta e indireta de conhecidos e amigos, muitos do próprio bairro. Uma vez encerradas as atividades da feira pela Prefeitura, "C" relata que sair de "porta em porta" para vender seu produto seria muito difícil, encerrando assim suas atividades, passando a viver da pensão de seu marido e da renda de trabalhos temporários eventuais.

Com 32 anos de idade, a quarta empreendedora " $D$ " é solteira e mora com os pais na região do Barreiro em Belo Horizonte. Com curso superior completo de enfermagem, trabalha, atualmente, à noite, como enfermeira em hospital público, e, durante o dia, em uma empresa de telefonia. Segundo seus relatos, a sua renda não era suficiente para sua sobrevivência. Sendo assim, buscou forma de complementá-la, passando a atuar, em 2014, no ramo de cosméticos, como revendedora dos produtos da empresa Mary Kay, vendendo seu produto nos contatos de trabalho, na vizinhança e para clínicas particulares, acessadas através de seus contatos.

Segundo ela, escolheu esta empresa, por ser muito reconhecida no mercado, e que, além disso, gosta muito de trabalhar com questões de beleza, tanto como negócio quanto para uso próprio. Relata, ainda, que acredita ter sido influenciada pela sua mãe que, durante um determinado período, foi revendedora. Tal atividade sobreviveu, de maneira sistemática, até meados de 2016. Depois disso, foi sendo desativada, aos poucos. Como conseguiu formar densa rede de relacionamentos pessoais e profissionais, as pessoas continuaram recorrendo a ela, para aquisição dos produtos. Manteve para isso, pequeno estoque em sua casa, que passou a utilizar, de forma não sistemática.

Segundo ela, sua falta de organização foi um dos principais motivos que a levou a dívidas crescentes e consequente desmotivação. Ela reconhece que não "corria atrás" e não se dedicava o suficiente para o sucesso do negócio. Ela pondera: "Eu acho que é assim, como toda empresa, se você não dedica você não consegue. Eu tinha que vender, eu tinha que divulgar, eu tinha que fazer seções demonstrativas e não fazia." Segundo seu relato, a estabilidade financeira (e pessoal) para ela estava ligada à possibilidade de realizar um concurso público, sonho que conseguiu realizar há cinco anos, quando pode ingressar como enfermeira em hospital público. O negócio no ramo de cosméticos não era sua prioridade.

A tabela a seguir (Tabela 3) resgata, de maneira resumida, evidências empíricas associadas a cada um dos fatores elencados no modelo teórico. Alguns destes fatores merecem análise minuciosa. Entre eles situam-se, dentro da categoria indivíduo, o fator personalidade; dentro da categoria atividade produtiva, os fatores planejamento e gestão; dentro da categoria ambiente sócio econômico, os fatores burocracia (onde insere-se a temática da formalização); competição; clientes; crise econômica.

$\mathrm{Na}$ dimensão indivíduo, observa-se que esses, no caso das ativas, demonstraram comprometimento com suas respectivas atividades. Tal situação talvez se explique devido ao fato das duas empreendedoras ativas dependerem, exclusivamente, de suas respectivas atividades para sua sobrevivência, diferentemente das extintas, onde a atividade era vista como possível forma de complementação de renda. Na dimensão atividade produtiva, observa-se, nos casos das ativas, um esforço mais sistemático de usar, ainda que de forma incipiente, algumas ferramentas de gestão; ou, mesmo, tentativa de recorrer, ainda que de maneira amadora, ao planejamento.

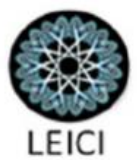


$\mathrm{Na}$ dimensão ambiente sócio econômico, o termo burocracia associa-se, na visão das entrevistadas, diretamente ao tema formalização. Embora todas demonstrem sentir certa rejeição, a empreendedora " $A$ " entende como "mal necessário" para seu crescimento, enquanto a empreendedora " $B$ " precisou se formalizar quando teve a oportunidade de realizar um trabalho melhor e em maior volume. Já as empreendedoras cujas atividades são vistas como "renda complementar" e cujas atividades foram extintas foram indiferentes quando abordadas sobre este assunto.

A concorrência também foi vista de forma divergente entre os grupos. No grupo das ativas, a concorrência foi abordada de forma respeitosa e colaborativa. Para as empreendedoras, são os concorrentes os maiores contribuintes para o aperfeiçoamento e o monitoramento da aceitação e qualidade dos seus produtos ou serviços. Ao contrário, para as empreendedoras cujas empresas foram extintas, a concorrência foi abordada com certo descaso. Para elas, além de não enxergarem a existência dos concorrentes, caso os mesmos existam, não eram passíveis de preocupação, considerando o diferencial e a qualidade dos seus produtos. Ressalta-se aqui, uma possível miopia ou desconhecimento destas empreendedoras do mercado no qual as estavam inseridas.

Alinhada com a temática da concorrência, abordamos a satisfação dos clientes, pois, naturalmente, o cliente insatisfeito tende a migrar para a concorrência mais próxima. Nesse ponto, o grupo das empreendedoras ativas demonstrou grandes preocupações com esse assunto. A empreendedora " $A$ " relatou a realização de entrevistas sistematizadas em parceria com ONGs que, além de formatarem as entrevistas para os clientes, aplicam, compilam os resultados e encaminham para a empreendedora. Da mesma forma, a empreendedora "B" realiza entrevistas pontuais junto aos clientes, além de acompanhar de forma rotineira os comentários postados nas redes sociais e em seu blog, criados também com esse intuito. Ao contrário, as empreendedoras das atividades extintas não possuíam esse mesmo hábito. A empreendedora "C" não investigava tal satisfação, tendo como "termômetro" apenas se o cliente voltava a procurar por seus produtos. A empreendedora " $D$ " afirmou apenas que confiava na qualidade dos produtos Mary Kay e acreditava na satisfação dos clientes devido à "fama" da empresa.

Por fim, sobre os efeitos da crise econômica e da situação política na qual o país se encontra, a única empreendedora que alega estar sofrendo os impactos foi a empreendedora "A". Assim, supõe-se que os resultados foram mascarados por situações específicas percebidas durante as entrevistas. No caso da empreendedora "A" a sua resposta vai de encontro ao cenário vivenciado por ela nas feiras. Segundo "A" o "dinheiro sumiu" e as pessoas diminuíram significativamente as compras. No caso da empreendedora "B", o fato de afirmar que a crise não a afetou poderia estar sendo tamponado pelo momento pessoal em que vive, ou seja, ela mesma diminuiu a quantidade de atendimentos devido a uma grave doença da irmã, o que a impede de enxergar se a clientela se afastou por causa da crise. Quanto às empreendedoras " $\mathrm{C}$ " e "D", pode-se perceber que a extinção das empresas se deu um pouco de forma simultânea ao aparecimento da crise, o que pode ter ocultado seus efeitos, uma vez que a atividade se encerraria independentemente da crise.

Quadro 3. Evidências empíricas segundo as categorias e fatores elencados no modelo teórico

\begin{tabular}{l|l}
\hline Categorias & Fatores \\
\hline INDIVÍDUO & \\
\hline
\end{tabular}

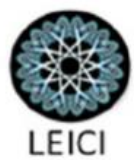




\begin{tabular}{|c|c|}
\hline $\begin{array}{l}\text { Experiência } \\
\text { prévia }\end{array}$ & $\begin{array}{l}\text { A experiência prévia não interferiu na mortalidade das atividades, mas contribuiu para o } \\
\text { sucesso de uma delas. }\end{array}$ \\
\hline Escolaridade & $\begin{array}{l}\text { A escolaridade não se apresentou como fator determinante para o sucesso das atividades } \\
\text { produtivas informais estudadas, assim como sua presença não impediu a mortalidade de } \\
\text { outras. }\end{array}$ \\
\hline Gênero & O gênero feminino foi dominante nas ativas e extintas. \\
\hline $\begin{array}{l}\text { Redes de } \\
\text { relacionamentos }\end{array}$ & $\begin{array}{l}\text { As redes de relacionamento foram consideradas importantes tanto na sobrevivência, } \\
\text { quanto na mortalidade. }\end{array}$ \\
\hline $\begin{array}{l}\text { Personalidade dos } \\
\text { indivíduos }\end{array}$ & $\begin{array}{l}\text { A personalidade se mostrou fator primordial para o sucesso das atividades ativas. } \\
\text { Ademais, coincidentemente ou não, as ativas, mantidas por indivíduos mais combativos e } \\
\text { batalhadores, eram, exatamente, aquelas que se constituíam na única fonte de renda e } \\
\text { sobrevivência dos envolvidos. }\end{array}$ \\
\hline \multicolumn{2}{|c|}{ ATIVIDADE PRODUTIVA } \\
\hline $\begin{array}{l}\text { Localização da } \\
\text { atividade }\end{array}$ & $\begin{array}{l}\text { Para as atividades de artesanato e alimento, a comercialização dos produtos em feiras } \\
\text { populares foi primordial para a sobrevivência das atividades. Quanto às demais atividades, } \\
\text { dependiam de visita aos clientes em casas, empresas ou outros locais. A localização, } \\
\text { portanto, impactou igualmente as atividades. }\end{array}$ \\
\hline $\begin{array}{l}\text { Presença } \\
\text { auxiliares }\end{array}$ & $\begin{array}{l}\text { A presença de auxiliares não foi constante durante a existência das atividades. Quando } \\
\text { presentes foram importantes. Não foi relatada a presença de algum apoio técnico } \\
\text { (contadores, advogados, etc.). Constata-se que sua presença ou ausência impacta } \\
\text { igualmente as atividades. }\end{array}$ \\
\hline Planejamento & $\begin{array}{l}\text { Percebe-se uma tendência ao uso do planejamento por parte dos negócios ativos, ainda } \\
\text { que de forma amadora ou incipiente. Ao contrário, a tendência não foi constatada nos } \\
\text { empreendedores cujas atividades morreram. }\end{array}$ \\
\hline Clientela & $\begin{array}{l}\text { De acordo com os relatos, os clientes são entendidos como o motivo da existência das } \\
\text { atividades. No entanto, apenas entre as ativas nota-se uma maior preocupação com a } \\
\text { observação da satisfação do cliente, inclusive através de formas mais estruturadas de } \\
\text { avaliação, pelo menos em um caso. }\end{array}$ \\
\hline $\begin{array}{l}\text { Ferramentas de } \\
\text { gestão }\end{array}$ & $\begin{array}{l}\text { É um fator inerente ao bom funcionamento das atividades, ainda que se apresente de forma } \\
\text { muito incipiente. Contudo, não percebemos evidências de que a ausência deste fator tenha } \\
\text { contribuído para o encerramento das atividades avaliadas. Por outro lado, percebe-se que } \\
\text { sua presença mais sistemática foi importante para o seu sucesso. }\end{array}$ \\
\hline Crédito & $\begin{array}{l}\text { Para as ativas, uma apresenta-se favorável e, aparentemente dependente do crédito ou de } \\
\text { outras alternativas (divisão dos custos variáveis), enquanto outra se manifestou de forma } \\
\text { desfavorável. No caso das extintas, uma delas se manifestou desfavorável, enquanto a } \\
\text { outra nos pareceu propensa a recorrer ao crédito para garantir a realização das atividades. } \\
\text { Nesse último caso, ficou evidente de que a falta de controle desse fator contribuiu } \\
\text { fortemente para o encerramento da atividade. }\end{array}$ \\
\hline Despesas/ custos & $\begin{array}{l}\text { As despesas das quatro atividades variam, em sua maioria, entre insumos, transporte, } \\
\text { alimentação. Considerando as despesas mencionadas, apenas uma das empreendedoras } \\
\text { ativas relatou ser este um fator impactante ao sucesso da atividade, ao contrário das } \\
\text { demais. }\end{array}$ \\
\hline Lucro & $\begin{array}{l}\text { Os resultados demonstram grande subjetividade desse conceito na perspectiva das } \\
\text { empreendedoras entrevistadas. Além disso, não se evidenciou a presença de técnicas } \\
\text { refinadas para a determinação do lucro, o que nos parece, num primeiro momento, ser } \\
\text { uma característica da tratativa do lucro no segmento das unidades produtivas informais na } \\
\text { população de baixa renda. }\end{array}$ \\
\hline $\begin{array}{l}\text { Disponibilidade } \\
\text { de produtos }\end{array}$ & $\begin{array}{l}\text { A presença ou não de estoque para as empreendedoras analisadas pode ser considerada } \\
\text { específica para cada caso. Para "A", por exemplo, poderia significar um aumento de } \\
\text { oportunidade de vendas e dos lucros. Para "B" indiferente. Para "C", no momento em que } \\
\text { a atividade funcionava com uma produção relativamente alta, a presença de estoque era }\end{array}$ \\
\hline
\end{tabular}


importante. Para "D" era essencial, pois, do contrário, não havia como fazer a demonstração do produto.

\begin{tabular}{l|l}
\hline AMBIENTE SÓCIO ECONÔMICO \\
\hline $\begin{array}{l}\text { Crise econômica } \\
\text { e social }\end{array}$ & $\begin{array}{l}\text { A conjuntura econômica isolada, de acordo com as respondentes, não pode ser } \\
\text { considerada um fator que influencia a sobrevivência ou a mortalidade das suas atividades. } \\
\text { Para elas, outros motivos são mais fortes e se sobrepõem a este, como por exemplo, força } \\
\text { de vontade, dedicação, empenho, diversidade de público, etc. }\end{array}$ \\
\hline Concorrência & $\begin{array}{l}\text { As ativas enxergam a concorrência de forma positiva e não a percebem como uma ameaça, } \\
\text { como possibilidade de aprendizado e melhoria dos seus próprios produtos. Para as } \\
\text { extintas, a natureza do negócio contribuiu para a redução da concorrência, ou até mesmo } \\
\text { a sua inexistência. Entendem que possuem produtos diferenciados, no local onde atuavam. }\end{array}$ \\
\hline Parcerias & $\begin{array}{l}\text { Quanto às parcerias entende-se que as mesmas são importantes para o sucesso dos } \\
\text { empreendimentos, uma vez que somente os empreendimentos que sobreviveram tiveram } \\
\text { parcerias efetivas. }\end{array}$ \\
\hline $\begin{array}{l}\text { Relação com os } \\
\text { fornecedores }\end{array}$ & $\begin{array}{l}\text { Não foi percebida nenhuma relação comercial diferenciada. Apesar disso, infere-se que o } \\
\text { fator "fornecedores" é determinante para a sobrevivência ou a mortalidade das atividades } \\
\text { estudadas. }\end{array}$ \\
\hline Burocracia & $\begin{array}{l}\text { Na percepção das empreendedoras, o termo é sinônimo de formalidade. Como motivos } \\
\text { para a não formalização foram citados o desânimo, a preguiça e a falta de tempo. Diante } \\
\text { desses resultados, percebe-se pouca ou quase nenhuma influência desse fator como } \\
\text { possível causador da sobrevivência ou da mortalidade. No entanto, percebe-se certa } \\
\text { rejeição à ideia de formalização, mais forte entre as ativas. }\end{array}$ \\
\hline
\end{tabular}

\section{CONSIDERAÇÕES FINAIS}

Os resultados gerais dessa pesquisa pioneira permitiram elucidar algumas dimensões relevantes do fenômeno analisado e avançar em importantes considerações. Em primeiro lugar, a população de baixa renda encontra muitas vezes nas unidades produtivas informais caminho alternativo para a inclusão social e para a busca pela subsistência. Se, por um lado, o ciclo da inclusão social se fortalece quando o indivíduo/empreendedor obtém sucesso em seu negócio, por outro, o insucesso tende a retroalimentar o ciclo da pobreza. Tal foi o identificado nos casos estudados.

Em segundo lugar, alguns dos fatores elencados na literatura acerca dos negócios formais também podem ser observados no contexto da informalidade, tais como o papel da experiência prévia, da personalidade, das redes de relacionamentos, os recursos da atividade produtiva, sua relação com parceiros, fornecedores, concorrentes, etc. Entretanto, a maior parte dos fatores, observados no contexto formal, não se aplica ao contexto informal. De fato, a abordagem do segmento informal exige a utilização de alguns novos conceitos. Dada a natureza muitas vezes precária, irregular e instável dessas atividades, os três construtos previamente elencados no modelo teórico aqui apresentado (indivíduo, atividade produtiva e ambiente sócio econômico) mostraram-se perfeitamente adequados.

Em terceiro lugar, embora essas três classes de fatores associados à sobrevivência e mortalidade possam, a princípio, ser sugeridas/identificadas e classificadas, estas encontramse, na prática, muitas vezes, bastante imbricadas umas às outras. Ou seja, existe grande interação entre certos elementos associados às características do indivíduo, à atividade produtiva e ao meio socioeconômico onde ele se insere. É assim, por exemplo, que a empreendedora A (e outras) faz de sua casa o local de produção; usa de um bem de consumo

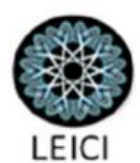


pessoal (por exemplo, seu fogão ou geladeira) como um bem de produção ou capital; teve em sua filha uma auxiliar; recorre a seus vizinhos ou conhecidos como parceiros na divisão dos riscos e benefícios de certas iniciativas produtivas. Ou, então, a empreendedora $\mathrm{C}$ ou $\mathrm{D}$ buscou seus colegas e conhecidos para acessar clientes, etc. Prevalece nesse segmento, uma mistura intensa entre dimensões de trabalho/renda, vida pessoal e contexto social, e também, entre trabalho e capital e entre vida social e mercado, etc.

Em quarto lugar, observa-se, nesse segmento, a presença de conceitos diferenciados, distinguindo a linguagem (consequentemente, a vivência) aí presente daquela linguagem (ou vivência) passível de ser observada no mundo dos negócios formais. É assim que uma das empreendedoras estudadas refere-se ao conceito de "sobras", ao invés de se referir ao conceito de lucro, amplamente utilizado no mundo dos negócios. Observa-se, em vários dos relatos, que esse público é permeado por vocabulários próprios e atitudes, talvez provenientes, em parte, da baixa escolaridade e da falta de experiência prévia no mundo dos negócios. Mas, talvez, prevaleça, também, nesse segmento, uma lógica diferente de se observar e apreender o mundo, como evidenciado no caso relatado da distribuição das "sobras", quando a empreendedora afirma que tudo "é divido em partes iguais para todos que trabalharam".

Em quinto lugar, o segmento apresenta uma dinâmica muito diferenciada, que repercute na própria lógica de sobrevivência e mortalidade. Não parece coincidência o fato das duas atividades ativas se constituírem, para os indivíduos envolvidos, na única e exclusiva fonte de renda. Consequentemente, eles não teriam outra opção, a não ser a de se desdobrar para se manterem ativos e garantir a própria sobrevivência. Diferentemente das duas atividades extintas, onde os indivíduos contavam com outras alternativas de renda, ainda que precárias. Ao mesmo tempo, uma atividade simplesmente não é encerrada, da noite para o dia. Ela vai sendo desativada aos poucos, enquanto o indivíduo se engaja em outras alternativas de renda. Assim, uma mesma atividade poderia se encontrar ativa em um determinado período, inativa em outro, para voltar à atividade, dependendo do ambiente e da conjuntura.

Em sexto lugar, dados de campo permitem sugerir que as fronteiras entre a informalidade e a formalidade são muito tênues e podem ser ultrapassadas com frequência, dependendo do ambiente de negócios. Dessa maneira, uma atividade pode se formalizar em um momento de certa expansão ou expectativa favorável, como foi o caso com a atividade $\mathrm{B}$, pode regredir à informalidade ou vice-versa. Como já observado, a fronteira entre a informalidade e as pequenas unidades produtivas formais é muito tênue, passível de ser atravessada em certos momentos, dependendo do ambiente e das condições da própria atividade. Observa-se que no próprio decorrer da seleção dos casos a serem pesquisados, grande parte dos contatos preliminares informou que, apesar de terem encerrado suas atividades, a crise os obrigou a retomá-las, mas, no entanto, não as considerava uma atividade bem-sucedida. O próprio conceito de atividade ativa ou não, sucesso ou fracasso no segmento deve ser visto de maneira relativa.

Esse conjunto de constatações atesta o carácter provocador e inovador do presente estudo, que foi capaz de avançar em contribuições de natureza analítica para o estudo do fenômeno de sobrevivência e mortalidade de negócios no segmento de baixa renda. Persistem, no entanto, limitações advindas da natureza da pesquisa realizada. Uma delas diz respeito ao tamanho e à peculiaridade da seleção utilizada. O total de quatro casos foi considerado o mínimo necessário para levar à cabo a pesquisa. Número maior de unidades empíricas de

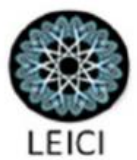


análises necessariamente serão mais interessantes, permitindo maior robustez na extrapolação por exaustão de evidências. No caso dessa presente pesquisa, isso não foi possível, como salientado, por resistência dos indivíduos a abordarem o tema da informalidade. Outro ponto diz respeito ao papel do gênero, que pode ser considerado um viés da presente pesquisa. Isso ocorreu dada a natureza da clientela atendida pela Rede Cidadã, constituída, predominantemente, de mulheres. No entanto, os homens atuam, certamente, em uma parcela significativa das atividades informais. Tais pontos devem ser abordados em futuras pesquisas.

Também restam lacunas a serem sanadas, conclamando por novas pesquisas, que poderiam investigar, por exemplo: i) Quais os motivos que levam os indivíduos a saírem da informalidade e a retornarem a ela? ii) Quais os perfis das redes mais utilizadas e sua importância no contexto da informalidade? iii) Qual o impacto dos tributos na formalização dos informais? iv) Quais os possíveis impactos de maior apoio técnico e de melhores políticas públicas nas atividades produtivas informais de baixa renda? Essas pesquisas poderão não apenas contribuir para uma melhor consolidação de conceitos e compreensão desse espaço desordenado, complexo e peculiar, como, também, para o aperfeiçoamento de políticas públicas e programas voltados para a erradicação da pobreza, a autonomia da população carente e o consequente aumento da inclusão social no Brasil.

\section{REFERÊNCIAS}

Aaboen, L., Dubois, A., \& Lind, F. (2012). Capturing processes in longitudinal multiple case studies. Industrial Marketing Management, 41(2), 235-246.

Albuquerque, A. F. (2013). Fatores de mortalidade de pequenas empresas: análise de Escola de Engenharia de São Carlos, Universidade de São Paulo, São Carlos, SP.

Bauer, M., Gaskell, G., \& Allum, N. C. (2002). Qualidade, quantidade e interesses do conhecimento: evitando confusões. In M. Bauer., \& G. Gaskell (Eds.)., Pesquisa Qualitativa com Texto, Imagem e Som: um manual prático (pp. 17-36). Petrópolis: Vozes.

Bonoma, T. V. (1985). Case Research in Marketing: Opportunities, Problems, and a Process. Journal of Marketing Research, 22(2), 199-208.

Cazarini, E. W.; Santos, E. M.; Oliveira Neto, J. D., \& Oliveira, S. R. M. (2008). Fatores de sucesso e insucesso do pequeno empreendedor: um olhar sobre seus tipos de personalidade e estilos de aprendizagem. São Paulo: EGEPE.

Creswell, J. W. (2007). Projeto de Pesquisa: métodos qualitativo, quantitativo e misto (pp. 184-210). Porto Alegre: Artmed

Dias, C. A.; Gonçalves, R. E. A., \& Augusto, H. A. (2014). Contextualizando a relação natividade versus mortalidade de micro e pequenas empresas no Brasil. In: $8^{\circ}$ Fórum de Ensino, Pesquisa e Extensão da Unimontes. Montes Claros/MG.

Dutra, I. S., \& Previdelli, J. J. (2005). Fatores condicionantes da mortalidade de empresas: um estudo dos empreendedores de micro e pequenas empresas paranaenses. Revista Capital Científico, 3(1), pp. 29-50.

Eckert, A.; Mecca, M. S.; Blasio, R., \& Macari, T. D. (2013). Gestão de pequenas empresas: identificação de mortalidade das empresas em um município da Serra Gaúcha. Revista Escola de Negócios (REN), 1(1), pp. 1-16. 
Ferreira, A. (2009). Favelas no Rio de Janeiro: nascimento, expansão, remoção e, agora, exclusão através de muros. Revista Bibliográfica de Geografia Y Ciências Sociales, 14 (828).

Ferreira, L. F. F.; Santos, S. A.; Oliva, F. L.; Grisi, C. C. H., \& Lima, A. C. (2012). Análise quantitativa sobre a mortalidade precoce de micro e pequenas empresas da cidade de São Paulo. Revista Gestão da Produção, 19(4), pp. 811-823.

Gaskell, G. (2002). Entrevistas individuais e grupais. In M. Bauer, \& G. Gaskell (Eds.), Pesquisa Qualitativa com Texto, Imagem e Som: um manual prático (pp. 64-83). Petrópolis: Vozes

Global Entrepreneurship Monitor- GEM. (2011). Empreendedorismo no Brasil. Acesso em

:http://www.sebrae.com.br/Sebrae/Portal\%20Sebrae/Anexos/Livro\%20GEM\%20Brasil\%202 011.pdf

Godoy, A. S. (1995a). A pesquisa qualitativa e sua utilização em administração de empresas. Revista de administração de empresas, 35(4), 65-71. Recuperado de http://www.scielo.br/pdf/rae/v35n4/a08v35n4.pdf

Godoy, A. S. (1995b). Introdução à pesquisa qualitativa e suas possibilidades. Revista de administração de empresas, 35(2), 57-63. Recuperado de http://rae.fgv.br/sites/rae.fgv.br/files/artigos/10.1590_S0034-75901995000200008.pdf

Godoy, A. S. (1995c). Pesquisa qualitativa: tipos fundamentais. Revista de administração de empresas, 35(3), 20-29. Recuperado de http://rae.fgv.br/sites/rae.fgv.br/files/artigos/10.1590_S0034-75901995000300004.pdf

Godoy, A. S. (2005). Refletindo sobre critérios de qualidade da pesquisa qualitativa. Gestão.Org - Revista Eletrônica de Gestão Organizacional, 3(2), 85-94. Recuperado de http://www.revista.ufpe.br/gestaoorg/index.php/gestao/article/view/136

Godoy, A. S. (2006). Estudo de caso qualitativo. In C. K. Godoi, R. Bandeira-de-Mello, \& A. Barbosa (Orgs), Pesquisa qualitativa em estudos organizacionais: paradigmas, estratégias e métodos (pp. 115-146). São Paulo: Saraiva

Leone, (2010). O perfil dos trabalhadores e trabalhadoras na economia informal no Brasil. Brasília: OIT.

Maia, C. E. S. (1999). Informalidade e Ilegalidade: faces e disfarces na economia urbana. Boletim Goiano de Geografia, 19 (2), pp. 99-117.

Marques, E. C. (2010). Redes sociais, segregação e pobreza. São Paulo: UNESP.

Márquez, P., Reficco, E., \& Berger, G. (2010). Negócios inclusivos: iniciativas de mercado con los pobres de Iberoamérica.

Meyer, C. B. (2001). A case in case study methodology. Field methods, 13(4), 329-352. Retrieved from http://fmx.sagepub.com/content/13/4/329.abstract. doi: $10.1177 / 1525822 \mathrm{X} 0101300402$

Minayo, M. C. S. de., Souza, E. R. de., \& Santos, N. J. dos. (2005). Avaliação por triangulação de métodos: abordagem de programas sociais (pp. 71-103). Rio de Janeiro: Fiocruz

Montenegro, M. R. (2013). Reflexões para uma teoria da localização da economia de insucesso de projetos de novos empreendimentos: um estudo com dados da Kauffman firm survey. Revista de Gestão e Projetos, 3(1).

Pamplona, J. B., \& Romeiro, M. C. (2002). Desvendando o setor informal: relatos de uma experiência brasileira. Revista da ABET, 2(22). 
Pochmann, M. (2008). O emprego no desenvolvimento da nação. São Paulo: Boitempo.

Portes, A., \& Schauffler, R. (1993). De la mano de obra excedente a la empresa dinâmica: perspectivas de competência del sector informal latinoamericano. Estudios Sociológicos, 11(33), pp. 817-850.

Rakowski, C. A. (1994). Convergence and Divergence in the Informal Sector Debate: a Focus on Latin America, Ohio State University: Columbus.

Rede Cidadã. (2015). Voluntários em Rede: guia de apoio ao mentor voluntário, Belo Horizonte/MG.

Relatório anual do Banco Mundial (2015). Recuperado em 30/04/2016 de: https://openknowledge.worldbank.org/bitstream/.../WBAnnualReport2015PT.pdf.

Ridder, H., Hoon, C., \& McCandless, A. (2009). The theoretical contribution of case study research to the field of strategy and management. Research Methodology in Strategy and Management, 5, 137-175.

Santos, A. L. (2006). Trabalho em pequenos negócios no Brasil: impactos da crise do final do século XIX. (Tese Doutorado). Instituto de Economia, Universidade Estadual de Campinas, Campinas.

Santos, A. L.; Krein, J.D.; Calixtre, A. B. Org. (2012). Micro e pequenas empresas: mercado de trabalho e implicação para o desenvolvimento, Rio de Janeiro: Ipea.

Santos, J. B. F.; Maciel, R.H.M.O.; Sato, L., \& Santos, J. B. F. (2014). Trabalhadores informais e a formação de redes socioprodutivas (RSP): considerações teórico-empíricas. Revista Contemporânea, 2(4).

Sen, A. K. (2010). Desenvolvimento como liberdade. São Paulo: Companhia das Letras.

Serviço Brasileiro de Apoio às Micro e Pequenas Empresas - SEBRAE (2007). Dez anos de monitoramento da sobrevivência e mortalidade de empresas. São Paulo: SEBRAE/SP.

Serviço Brasileiro de Apoio às Micro e Pequenas Empresas (2011). Taxa de Sobrevivência das Empresas no Brasil. (Coleção Estudos e Pesquisas). Brasília: SEBRAE Nacional.

Theodoro, M. (2000). As bases da política de apoio ao setor informal no Brasil. Brasília: IPEA.

Valarelli, M. M., \& Vale, G. M. V. (1997). Informalidade e cidadania: empreendimentos informais no Rio de Janeiro. Rio de Janeiro: IBASE.

Vale, G. M. V., Aguiar, M. A. S., \& Andrade, N. A. (1998). Fatores condicionantes da mortalidade de empresas. Brasília: Edições Sebrae.

Vianna, M. O. S.; Teixeira, R. M., \& Franca, V. V. (2013). Perfil dos empreendedores individuais e características dos negócios formalizados pelo programa EI em Aracaju, Sergipe. Revista Pensamento Contemporâneo em Administração, Rio de Janeiro, 7 (2), pp. 19-40.

Voss, C., Tsikriktsis, N., \& Frohlich, M. (2002). Case research in operations management. International Journal of Operations \& Production Management, 22(2), 195-219.

Warren, I. S. (2003). A problemática da pobreza na construção de um movimento cidadão. Revista Política e Sociedade, 2(3). Bookman.

Yin, Robert K. (2010). Estudo de caso: Planejamento e métodos. (5a ed.). Porto Alegre: 